\title{
A randomised, phase II trial of the DNA-hypomethylating agent 5-aza-2'-deoxycytidine (decitabine) in combination with carboplatin vs carboplatin alone in patients with recurrent, partially platinum-sensitive ovarian cancer
}

R M Glasspool*,1, R Brown ${ }^{2}$, M E Gore ${ }^{3}$, G J S Rustin ${ }^{4}$, I A McNeish ${ }^{5}, \mathrm{R} \mathrm{H} \mathrm{Wilson}^{6}$, S Pledge ${ }^{7}, \mathrm{~J} \mathrm{Paul}^{1}$, M Mackean ${ }^{8}$, G D Hall ${ }^{9}$, H Gabra ${ }^{2}$, S E R Halford ${ }^{10}$, J Walker ${ }^{11}$, K Appleton ${ }^{11}$, R Ullah ${ }^{11}$ and S Kaye ${ }^{3}$ on behalf of the Scottish Gynaecological Trials Group

${ }^{1}$ The Beatson West of Scotland Cancer Centre, 1053 Great Western Road, Glasgow G12 OYN, UK; ${ }^{2}$ Department Surgery and Cancer, Imperial College London, Hammersmith Hospital, London W12 ONN, UK; ${ }^{3}$ Royal Marsden NHS Foundation Trust, Downs Road, Sutton, Surrey SM2 5PT, UK; ${ }^{4}$ Mount Vernon Cancer Centre, Northwood, Middlesex HA6 2RN, UK; ${ }^{5}$ St Bartholomew's Hospital, West Smithfield, London EC1A 7BE, UK; ${ }^{6}$ Centre for Cancer Research and Cell Biology, Queen's University Belfast, Belfast BT9 7AB, N. Ireland, UK; ${ }^{7}$ Sheffield Weston Park Hospital, Whitham Road, Sheffield, South Yorkshire S10 2SJ, UK; ${ }^{8}$ Edinburgh Western General Hospital, Crewe Road S, Edinburgh EH4 2XU, UK; ${ }^{9}$ St James's Institute of Oncology, St James's University Hospital, Beckett Street, Leeds LS9 7TF, UK; ${ }^{10}$ Drug Development Office Cancer Research UK, Angel Building, 407 Street, John Street, Islington, London EC1V 4AD, UK and ${ }^{11}$ Analytical Services Unit, Wolfson Wohl Cancer Research Centre, Institute of Cancer Sciences, University of Glasgow, Garscube Estate, Glasgow G61 1QH, UK

Background: Our previous laboratory and clinical data suggested that one mechanism underlying the development of platinum resistance in ovarian cancer is the acquisition of DNA methylation. We therefore tested the hypothesis that the DNA hypomethylating agent 5-aza-2'deoxycytodine (decitabine) can reverse resistance to carboplatin in women with relapsed ovarian cancer.

Methods: Patients progressing 6-12 months after previous platinum therapy were randomised to decitabine on day 1 and carboplatin (AUC 6) on day 8 , every 28 days or carboplatin alone. The primary objective was response rate in patients with methylated hMLH1 tumour DNA in plasma.

Results: After a pre-defined interim analysis, the study closed due to lack of efficacy and poor treatment deliverability in 15 patients treated with the combination. Responses by GCIG criteria were 9 out of 14 vs 3 out of 15 and by RECIST were 6 out of 13 vs 1 out of 12 for carboplatin and carboplatin/decitabine, respectively. Grade 3/4 neutropenia was more common with the combination (60\% vs 15.4\%) as was G2/3 carboplatin hypersensitivity (47\% vs $21 \%)$.

Conclusions: With this schedule, the addition of decitabine appears to reduce rather than increase the efficacy of carboplatin in partially platinum-sensitive ovarian cancer and is difficult to deliver. Patient-selection strategies, different schedules and other demethylating agents should be considered in future combination studies.

*Correspondence: Dr RM Glasspool; E-mail: ros.glasspool@ggc.scot.nhs.uk

Received 26 November 2013; revised 5 February 2014; accepted 9 February 2014; published online 18 March 2014

(c) 2014 Cancer Research UK. All rights reserved 0007-0920/14 
Ovarian cancer accounted for an estimated 140000 deaths worldwide in 2008 (Ferlay et al, 2010). Most women present with advanced disease, and although initially chemosensitive, the majority of tumours recur with ultimate failure of conventional cytotoxic drugs. Thus acquired resistance represents a major clinical challenge, and an understanding of the mechanisms involved may offer the opportunity for therapeutic intervention.

Alteration of the epigenetic state of tumour cells offers one mechanism by which resistance may develop (Glasspool et al, 2006). Aberrant methylation and associated transcriptional silencing of genes is frequently seen in ovarian tumours and is seen more often in cells that acquire drug resistance following chronic exposure to cisplatin (Dai et al, 2008; Chang et al, 2010). Methylation of a subset of genes is associated with short progression-free survival (PFS) following chemotherapy (Wei et al, 2006). However, promoter methylation of certain genes has also been implicated in sensitivity to chemotherapy (Zeller and Brown 2010), suggesting that it may be necessary to identify specific methylation profiles that are associated with drug resistance and sensitivity.

A relatively small number of genes that are potential drivers of platinum resistance (Zeller et al, 2012) have been identified by combined expression and methylation profiling following treatment of ovarian cell line models with the demethylating agent 5-aza-2'-deoxycitidine (decitabine). One of these key loci is MLH1 where DNA methylation and resulting loss of expression of this DNA mismatch repair gene may decrease response to chemotherapy (Brown et al, 1997). In drug-resistant xenograft tumour models with methylated $M L H 1$, the methyltransferase (DNMT) inhibitor, decitabine, induces re-expression of MLH1 and sensitises the drugresistant tumour xenografts to carboplatin (Plumb et al, 2000). In vivo, methylation and loss of MLH1 expression occur at higher frequency in post chemotherapy compared with pre-chemotherapy samples (Strathdee et al, 1999). Methylation of MLH1 is increased in plasma DNA samples of patients with EOC at relapse following first-line carboplatin/taxane chemotherapy compared with matched pre-chemotherapy samples. Furthermore, acquisition of MLH1 methylation in plasma DNA at relapse is an independent predictor of poor overall survival (OS; Gifford et al, 2004). Thus we hypothesised that acquired methylation and associated gene silencing, particularly of the $M L H 1$ promoter, during chemotherapy contributes to acquired platinum resistance in EOC and that this could be reversed by decitabine.

A phase I study demonstrated the feasibility of a 4 weekly schedule where decitabine $90 \mathrm{mg} \mathrm{m}^{-2}$ was given on day 1 and carboplatin (AUC 6) on day 8, to allow time for demethylation and re-expression of methylated genes before administration of carboplatin (Appleton et al, 2007). Here we describe a randomised phase II trial using this dose and schedule $v s$ carboplatin alone in women with EOC, relapsing 6-12 months after previous platinumbased chemotherapy.

\section{PATIENTS AND METHODS}

Study design. This was a multicentre, open label, randomised phase II study, sponsored by Cancer Research UK. The study was conducted according to the principles of good clinical practice and in accordance with the Declaration of Helsinki and approved by an ethical review committee. Patients gave written informed consent. The primary objective was to estimate response rate (RR) by GCIG criteria (Rustin et al, 2011) in patients with methylated $h M L H 1$ CGI DNA in plasma. Secondary objectives were: RR regardless of methylation status; PFS and OS; safety and tolerability; feasibility; incidence of hypersensitivity reactions; and the relationship between peak plasma levels of decitabine and global or $\mathrm{CpG}$ island-specific methylation. The primary end point was defined as any response (PR or CR) in patients with methylated hMLH1 CGI DNA in plasma as determined by RECIST criteria or, in patients without measurable disease, by CA-125 levels. The best overall response combining CA-125 and RECIST was determined using the GCIG guidelines from November 2005 (Rustin et al, 2011). The secondary end points were defined as follows. Overall RR was any response ( $\mathrm{PR}$ or $\mathrm{CR}$ ) in any of the patients as determined by RECIST criteria or in patients without measurable disease by CA-125 levels. The best overall response combining CA-125 and RECIST was determined using the GCIG guidelines from November 2005. PFS was defined as the time from randomisation to progression or death from any cause (whichever occurs first). Patients who did not experience either of these events were censored at the last date of follow-up. OS was defined as time from randomisation to death from any cause. Patients who did not experience either of these events were censored at the last date of follow-up. Causality of each adverse event to decitabine and/or carboplatin and grade severity was defined according to CTCAE Version 3.0. Further end points were the total dose and dose intensity of carboplatin and decitabine received, the incidence of grade 3 and 4 hypersensitivity reactions, the plasma levels of decitabine $1 \mathrm{~h}$ after the start of the decitabine infusion in the combination arm and global levels and CpG island-specific DNA methylation in peripheral mononuclear cells.

Eligibility. Eligibility criteria were as follows: EOC, fallopian tube cancer or primary peritoneal cancer; age $>18$ years; a maximum of two previous lines of treatment: a platinum regimen as their most recent treatment; initial response by RECIST and/or CA-125 criteria but relapse 6-12 months after last platinum treatment; measurable disease by RECIST and/or by GCIG CA-125 criteria; PS (WHO) 0-2; and haematological and biochemical indices within standard ranges. Patients were excluded if considered intolerant to carboplatin AUC 5 due to excessive myelotoxicity or hypersensitivity reaction.

Treatment plan. Women were randomised between: (A) Carboplatin (AUC 6 based on GFR measured by radioisotope assay) intravenously on $\mathrm{d} 1$ every 28 days or (B) decitabine $\left(90 \mathrm{mg} \mathrm{m}^{-2}\right.$ and subsequently $45 \mathrm{mg} \mathrm{m}^{-2}$ ) as a 6-h IV infusion on $\mathrm{d} 1$ and Carboplatin (AUC 6) on d8 every 28 days.

If the re-treatment criteria were not met on d1 (Arm A or Arm B) or on $\mathrm{d} 8$ (Arm B), treatment was delayed. If the delay was $\leqslant 7$ days, the doses were maintained, but if between 8 and 15 days the dose was reduced by one dose level. If re-treatment criteria were not met after 15 days, the patient was removed from the study. If patients experienced grade 4 neutropenia complicated by fever $\geqslant 38.5^{\circ} \mathrm{C}$; or lasting $\geqslant 7$ days; thrombocytopenia $\leqslant 25 \times 10^{9} 1^{-1}$; or any grade 3 or 4 non-haematological $\mathrm{AE}$, the dose was reduced by one level. Dose levels were Arm A: level - 1 AUC 5 carboplatin, level -2 remove from study; Arm B: dose level -1 decitabine $45 \mathrm{mg} \mathrm{m}^{-2}$, level -2 carboplatin AUC 5, level -3 stop decitabine and continue carboplatin alone. Prophylactic use of growth factors was not permitted.

Statistical methods. Patients were randomised $1: 1$ between the study arms, using a minimisation algorithm incorporating a random component (Scott et al, 2002). Stratification factors were first-line treatment received, number of previous lines of treatment, WHO PS and assessable disease criteria.

The planned recruitment was 134 patients, which was estimated to allow inclusion of approximately 40 patients with methylated MLH1 DNA in plasma assuming a methylation rate of $30 \%$ (derived from our previous study of patients relapsing after firstline therapy (Gifford et al, 2004)). This would enable a difference in RR between the two arms to be estimated with a s.e. of $12 \%$ and give an $85 \%$ probability that the response difference favoured the 
combination arm, assuming RR of $10 \%$ and $25 \%$, respectively, on the carboplatin and combination arms in women with methylated MLH1 DNA in plasma. With the total sample of 134 , the difference in overall RR between the two arms could be estimated with a s.e. of $8 \%$ and give an $96 \%$ probability that the response difference in the overall population favoured the combination assuming a RR in the carboplatin alone group of $25 \%$ rising to $40 \%$ in the combination arm. There was an early stopping rule if no responses were seen in the first 11 patients in the combination arm. The probability of stopping at this point was $<5 \%$ if the true RR was $>25 \%$. As the study was closed early because of observed poor response and tolerability of the combination arm, the $P$-values for comparison of the end points between the arms will be more extreme than they would be for a non-data-prompted analysis.

The Kruskal-Wallis test was used to compare neutropenia grades and relative carboplatin dose intensity. Spearman's rank correlation was used to examine the associations between day 1 decitabine concentration and minimum global methylation and area above the methylation curve. Kaplan-Meier techniques were used to estimate PFS.

Collection of pharmacokinetic and pharmacodynamic samples. Assays integral to the primary or secondary objectives of the trial were conducted using validated standard operating procedures. Assays were performed as previously described (Gifford et al, 2004; Appleton et al, 2007).

\section{RESULTS}

Patients. Twenty-nine patients had entered the study when the first efficacy analysis was performed. The first four patients in Arm $\mathrm{B}$ at $90 \mathrm{mg} \mathrm{m}^{-2}$ decitabine (B90) all required a dose delay of 1-2 weeks before cycle 2, and three required a dose reduction of decitabine. In contrast, only one of the five patients in Arm A (carboplatin alone) recruited during the same time period required a delay of 1 week with no dose reductions. The starting dose of decitabine was therefore reduced to $45 \mathrm{mg} \mathrm{m}^{-2}$ for subsequent patients (B45). Allowing for the relatively small numbers in the groups, there was no marked imbalance between the arms (Table 1).

\begin{tabular}{|c|c|c|c|}
\hline & $\begin{array}{c}\text { Arm A, } \\
n=14\end{array}$ & $\begin{array}{l}\text { Arm } \\
\text { B90, } \\
n=4\end{array}$ & $\begin{array}{c}\text { Arm } \\
\text { B45, } \\
n=11\end{array}$ \\
\hline Mean age (years) & 57.7 & 60 & 59.5 \\
\hline $\begin{array}{l}\text { Median time from last platinum treatment to } \\
\text { first/second relapse (months) }\end{array}$ & 8.05 & 7.12 & 8.02 \\
\hline \multicolumn{4}{|l|}{ Type of first-line chemotherapy (\%) } \\
\hline Platinum alone & 21.4 & 0 & 27.3 \\
\hline Platinum plus taxane & 78.6 & 75 & 72.7 \\
\hline Platinum plus other & 0 & 25 & 0 \\
\hline \multicolumn{4}{|l|}{ Response to most recent treatment (\%) } \\
\hline Complete response & 50 & 50 & 18.2 \\
\hline Partial response & 42.9 & 50 & 45.5 \\
\hline Stable disease & 0 & 0 & 18.2 \\
\hline Adjuvant & 7.1 & 0 & 18.2 \\
\hline \multicolumn{4}{|l|}{ Number of lines of previous treatment } \\
\hline 1 & 92.9 & 75 & 90.9 \\
\hline 2 & 7.1 & 25 & 9.1 \\
\hline
\end{tabular}

Feasibility. In Arm A, 8 of the 14 patients completed six or more cycles. In contrast, no patients in Arm B received six cycles of decitabine and carboplatin. The reasons for stopping assigned treatment are shown in Table 2.

Dose delays and reductions. Dose delays due to clinical reasons are shown in Table 2. The most common cause of dose delay overall was neutropenia (two patients (three episodes) in A, four patients (six episodes) in B90 and four patients (four episodes) in B45). Delay in starting cycle 2 due to neutropenia was more common in the combination arm with one patient in Arm A, four in B90 and four in B45. The dose of decitabine was reduced in three patients on B90. In B45, three patients stopped decitabine due to toxicity, continuing with carboplatin alone. Reductions in carboplatin were similar across arms.

Adverse events. The most noteworthy adverse events were hypersensitivity and neutropenia. Grade 3/4 neutropenia was seen in $100 \%, 45.5 \%$ and $15.4 \%$ on B90, B45 and A respectively. The difference in nadir neutropenia was statistically significant across all arms but not between Arm A and B45 $(P=0.008$ and $P=0.172$, respectively), indicating that the difference was mainly due to $\mathrm{B} 90$ patients. Ten patients in the combination experienced hypersensitivity reactions (17 episodes) compared with 3 patients in Arm A (6 episodes). Although patients were given a desensitising regime

Table 2. Number of cycles of assigned chemotherapy completed, reason for stopping assigned treatment before six cycles, dose delays and dose reductions by treatment arm

\begin{tabular}{|c|c|c|c|}
\hline & $\begin{array}{c}\text { Arm A, } \\
n=14\end{array}$ & $\begin{array}{c}\text { Arm B90, } \\
n=4\end{array}$ & $\begin{array}{c}\text { Arm B45, } \\
n=11\end{array}$ \\
\hline
\end{tabular}

Total number of cycles received (as per protocol)

\begin{tabular}{|l|c|c|c|}
\hline 1 cycle & 3 & 0 & $3^{\mathrm{a}}$ \\
2 cycles & 0 & $3^{\mathrm{b}}$ & 3 \\
3 cycles & 0 & 0 & 0 \\
4 cycles & 2 & $1^{\mathrm{c}}$ & $3^{\mathrm{c}}$ \\
5 cycles & 1 & 0 & 2 \\
6 cycles & 7 & 0 & 0 \\
7 cycles & 1 & 0 & 0
\end{tabular}

Reason for stopping assigned treatment before six cycles

Progressive disease

Neutropenia

Neutropenia and

Thrombocytopenia

Hypersensitivity to carboplatin

Nausea and fatigue

Decitabine withdrawn when

study terminated early

Number of patients with clinical dose delays lasting $\geqslant 7$ days

\begin{tabular}{|c|c|c|c|}
\hline Cycle at which delay occurred & Arm A & Arm B90 & Arm B45 \\
\hline 2 & 3 & $3^{\text {d }}$ & $5^{\text {d }}$ \\
3 & 1 & 1 & 0 \\
4 & 1 & 1 & 2 \\
5 & 1 & 0 & 0 \\
\hline
\end{tabular}

Number of patients with carboplatin dose reductions

1 dose reduction

2 dose reductions

1
2

2

0

2

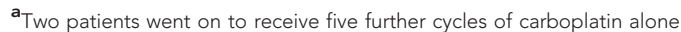

${ }^{b}$ One patient went on to receive two further cycles of carboplatin alone.

${ }^{c}$ One patient went on to receive two further cycles of carboplatin alone.

${ }^{\mathrm{d}}$ One further patient had a delay of $<7$ days. 
following a carboplatin hypersensitivity reaction, more patients stopped treatment due to hypersensitivity reactions to carboplatin in Arm B than in Arm A (4 vs 1). (See Table 3 for other adverse events).

Dose intensity. There was no significant difference in total dose of carboplatin between the arms (A: median 32.67 AUC (interquartile range 17.03-36.05); B90: 18.04 (9.75-28.57); B45: 23.05 (11.97-35.81) $(P=0.430))$. There was a statistically significant difference in carboplatin relative dose intensity between all three arms (A 95.85 (89.43-100); B90: 79.17 (69.27-87.79); B45: 90.07 (85.39-96.55; $P=0.031)$ but not between $\mathrm{A}$ and $\mathrm{B} 45(P=0.378)$, indicating that the difference was due to the difference between $\mathrm{B} 90$ and $\mathrm{A}$.

Efficacy. By combined GCIG (CA125) criteria, 9 out of 14 in Arm A $v s 3$ out of 15 in the combination arm responded $(P=0.025)$. Twenty-five patients were evaluable by RECIST criteria, 7 out of 13 patients had a response ( $1 \mathrm{CR}, 6 \mathrm{PR})$, in Arm A and 1 out of 12 in the combination arm. $(P=0.072)$ (Table 4$)$. The median response

Table 3. Adverse events by treatment arm including grade 2 or above toxicity where grade 2 or above toxicity occurred in at least $5 \%$ of patients and grade 1 or above hypersensitivity reactions

\begin{tabular}{|c|c|c|c|c|}
\hline \multirow[t]{2}{*}{ Adverse event } & \multirow[t]{2}{*}{ Grade } & Arm A & Arm B90 & Arm B45 \\
\hline & & \multicolumn{3}{|c|}{$\%$ (no of patients) } \\
\hline \multirow[t]{2}{*}{ Haemoglobin } & 2 & $30.8(4)$ & 0 & $45.5(5)$ \\
\hline & 4 & $7.7(1)$ & 0 & $9.1(1)$ \\
\hline Infection with unknown ANC & 2 & $7.1(1)$ & 0 & $18.2(2)$ \\
\hline \multirow[t]{2}{*}{ Leucopenia } & 2 & $30.8(4)$ & $25(1)$ & $45.5(5)$ \\
\hline & 3 & 0 & 75 (3) & $9.1(1)$ \\
\hline \multirow{2}{*}{ Lymphopenia } & 2 & $7.7(1)$ & 25 (1) & $9.1(1)$ \\
\hline & 3 & $7.7(1)$ & $25(1)$ & $9.1(1)$ \\
\hline \multirow[t]{3}{*}{ Neutropenia } & 2 & $46.2(6)$ & 0 & 27.3 (3) \\
\hline & 3 & $15.4(2)$ & $25(1)$ & $36.4(4)$ \\
\hline & 4 & 0 & $75(3)$ & $9.1(1)$ \\
\hline \multirow[t]{3}{*}{ Thrombocytopenia } & 2 & $7.7(1)$ & 0 & 0 \\
\hline & 3 & 0 & 0 & $9.1(1)$ \\
\hline & 4 & $15.4(2)$ & 0 & $9.1(1)$ \\
\hline Nausea & 2 & $14.3(2)$ & $25(1)$ & $27.3(3)$ \\
\hline Vomiting & 2 & $14.3(2)$ & 0 & $18.2(2)$ \\
\hline Pain & 2 & 0 & 0 & $27.3(3)$ \\
\hline \multirow[t]{3}{*}{ Hypersensitivity } & 1 & 0 & $25(1)$ & $18.2(2)$ \\
\hline & 2 & $7.1(1)$ & $25(1)$ & $27.3(3)$ \\
\hline & 3 & $14.3(2)$ & $25(1)$ & $18.2(2)$ \\
\hline Constipation & 2 & 0 & 0 & $18.2(2)$ \\
\hline \multirow[t]{2}{*}{ Dyspnoea } & 3 & 0 & 0 & $9.1(1)$ \\
\hline & 4 & 0 & $25(1)$ & 0 \\
\hline Fatigue & 2 & $35.7(5)$ & $25(1)$ & $63.6(7)$ \\
\hline Hypoalbuminaemia & 2 & $7.7(1)$ & $25(1)$ & $27.3(3)$ \\
\hline \multirow{3}{*}{ GGT } & 2 & 7.7 (1) & 0 & 9.1 (1) \\
\hline & 3 & 0 & 0 & $18.2(2)$ \\
\hline & 4 & $7.7(1)$ & 0 & 0 \\
\hline AST & 2 & $15.4(2)$ & 0 & $9.1(1)$ \\
\hline \multirow[t]{2}{*}{ Hypophosphataemia } & 2 & $23.1(3)$ & 0 & $30(3)$ \\
\hline & 3 & 0 & 0 & $10(1)$ \\
\hline \multirow[t]{2}{*}{ Hyperglycaemia } & 2 & $15.4(2)$ & 0 & $27.3(3)$ \\
\hline & 3 & $7.7(1)$ & 0 & 0 \\
\hline $\begin{array}{l}\text { Abbreviations: } \quad A N C=\text { absolute } \\
\text { GGT }=\text { gamma glutamyl transferas }\end{array}$ & rophil & count; & $\mathrm{T}=$ aspartate & transaminase; \\
\hline
\end{tabular}

duration for carboplatin alone was 9.3 months (range 1.9 to $>19.5$ months) compared with 2.6 months (range 1.9-7.3 months) for B45. The median PFS was 6.9 months (95\% CI 4.3-9.4) for carboplatin alone, 1.9 months for B90 (0-9.4) and 6 months for B45 (95\% CI 1-11) (Figure 1). Only three patients had methylated MLH1), two in A (achieving CR and PR) and one in B90 (stable disease).

Study closure. A pre-planned formal assessment of tumour responses was performed after the first 11 patients had been recruited into $\mathrm{B} 45$. The one RECIST responder in fact only received one cycle of combination treatment followed by five cycles of carboplatin and two others had short-lived CA125 responses only and progressed before the end of treatment. In addition, the deliverability of B45 was difficult due to hypersensitivity and neutropenia. No patients in this arm completed six cycles as per protocol, indicating that treating sufficient patients in B45 to evaluate the study was very unlikely to be achievable. As a result, the decision was made to terminate the study.

Pharmacokinetics and pharmacodynamic end points. Pharmacokinetic data were available for 11 out of 15 patients in Arm B. The mean concentration of decitabine $1 \mathrm{~h}$ post infusion was $125.69 \mathrm{ng} \mathrm{ml}^{-1}(\sigma$ 58.46; range 84.18-192.55) for B90 and $53.17 \mathrm{ng} \mathrm{ml}^{-1}(\sigma$ 16.47; range 24.06-72.91) for B45.

Global 5-methyl-2'-deoxycytidine levels were measured in DNA from peripheral blood cells in all 29 patients. Decitabine resulted in a decrease in global levels of methylation, becoming maximal 10 days after decitabine and returning to baseline by day 22 (Figure 2). This was in contrast to the stable levels of global methylation observed with carboplatin alone. There was a statistically significant correlation between the concentration of decitabine $1 \mathrm{~h}$ after the start of the infusion and minimum global methylation (Spearman correlation coefficient $-0.65 ; P=0.037,90 \%$ CI -0.90 to -0.20$)$ and the area above the methylation curve (Spearman correlation coefficient $0.85 ; P=0.002,90 \%$ CI -0.56 to 0.96$)$.

\section{DISCUSSION}

Data from our group and others have indicated that DNA methylation-induced gene silencing may have a role both in the

\begin{tabular}{|c|c|c|c|c|}
\hline & Arm A & $\begin{array}{l}\text { Arm } \\
\text { B90 }\end{array}$ & $\begin{array}{l}\text { Arm } \\
\text { B45 }\end{array}$ & Total \\
\hline & & \multicolumn{3}{|c|}{$\%$ (no. of patients) } \\
\hline Complete response & $7.1(1)$ & $0(0)$ & $0(0)$ & $3.4(1)$ \\
\hline Partial response & $57.1(8)$ & $0(0)$ & $27.3(3)$ & $37.9(11)$ \\
\hline Stable disease & $28.6(4)$ & $50(2)$ & $45.5(5)$ & $41.4(12)$ \\
\hline Progressive disease & 0 & $50(2)$ & $18.2(2)$ & $10.3(3)$ \\
\hline Unevaluable & $7.1(1)$ & $0(0)$ & $9.1(1)$ & $6.9(2)$ \\
\hline Total & $100(14)$ & $100(4)$ & $100(11)$ & $100(29)$ \\
\hline Responses by RECIST alone & $\begin{array}{l}1 \mathrm{CR} \\
5 \mathrm{PR} \\
5 \mathrm{SD} \\
0 \mathrm{PD} \\
2 \mathrm{NE}\end{array}$ & $\begin{array}{l}0 \mathrm{CR} \\
0 \mathrm{PR} \\
1 \mathrm{SD} \\
2 \mathrm{PD} \\
0 \mathrm{NE}\end{array}$ & $\begin{array}{l}0 \mathrm{CR} \\
1 \mathrm{PR} \\
5 \mathrm{SD} \\
2 \mathrm{PD} \\
1 \mathrm{NE}\end{array}$ & $\begin{array}{c}1 \mathrm{CR} \\
6 \mathrm{PR} \\
11 \mathrm{SD} \\
4 \mathrm{PD} \\
2 \mathrm{NE}\end{array}$ \\
\hline
\end{tabular}




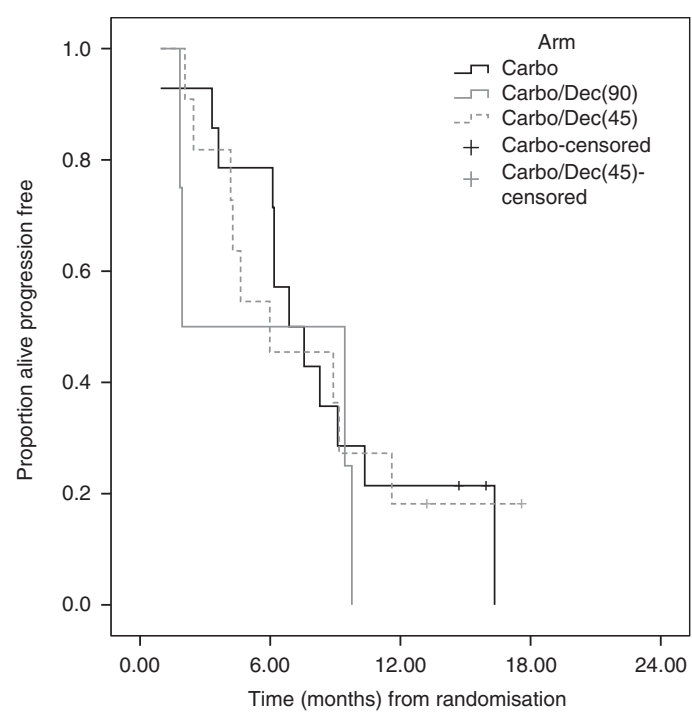

\begin{tabular}{|l|l|c|c|c|c|c|}
\hline & $\begin{array}{l}\text { Time } \\
\text { (months) }\end{array}$ & 0 & 6 & 12 & 18 & 24 \\
\hline \multirow{2}{*}{$\begin{array}{l}\text { No. } \\
\text { at } \\
\text { risk }\end{array}$} & Carbo & 14 & 11 & 3 & 0 & 0 \\
\cline { 2 - 6 } & $\begin{array}{l}\text { Carbo/ } \\
\text { Dec(90) }\end{array}$ & 4 & 2 & 0 & 0 & 0 \\
\cline { 2 - 6 } & $\begin{array}{l}\text { Carbo/ } \\
\text { Dec(45) }\end{array}$ & 11 & 5 & 2 & 0 & 0 \\
\hline
\end{tabular}

Figure 1. Progression-free survival.

development of resistance to cytotoxic chemotherapeutic agents and in the deterioration of drug sensitivity, according to the genes involved (Glasspool et al, 2006; Chang et al, 2010). Unlike genetic modification, epigenetic modifications require active maintenance and hence may be amenable to pharmacological intervention and reversal. Decitabine sequesters DNA methyltransferases, leading to demethylation of DNA following DNA replication. Decitabine has activity in MDS and AML, but its single agent activity in solid tumours has been disappointing (Graham et al, 2009). However, cell line and xenograft studies showed that demethylation of drugresistant tumours can lead to chemosensitisation (Plumb et al, 2000), and decitabine may be most effectively used in solid tumours in combination with cytotoxics, such as carboplatin. Older studies investigating the combination of cytotoxic agents and decitabine used maximally tolerated doses and schedules, which would not have allowed any demethylation, gene re-expression or drug sensitisation to occur before delivery of the cytotoxic agent. At higher doses, it has direct cytotoxic activity as a result of incorporation into DNA. However, its effects on demethylation and gene expression may be achieved at lower doses than the maximally tolerated dose (Kantarjian et al, 2007). In the present study, we used a schedule and dose of decitabine shown to induce equivalent demethylation in surrogate tissues at the time of carboplatin administration as that which re-induced platinum sensitivity in xenografts models (Plumb et al, 2000; Appleton et al, 2007).

The study included patients who had relapsed between 6 and 12 months following platinum therapy; we excluded patients with platinum-free interval of $<6$ months as our policy for those is to treat with non-platinum agents. Although randomised studies have indicated that carboplatin in combination with paclitaxel or gemcitabine improves overall or PFS compared with single agent carboplatin in relapsed patients with $\geqslant 6$-month platinum-free interval (Parmar et al, 2003; Pfisterer et al, 2006), combination therapy is not appropriate for all patients, and all the investigators in the study considered that single agent carboplatin was still an acceptable control arm in selected patients in this 6-12 month subgroup.
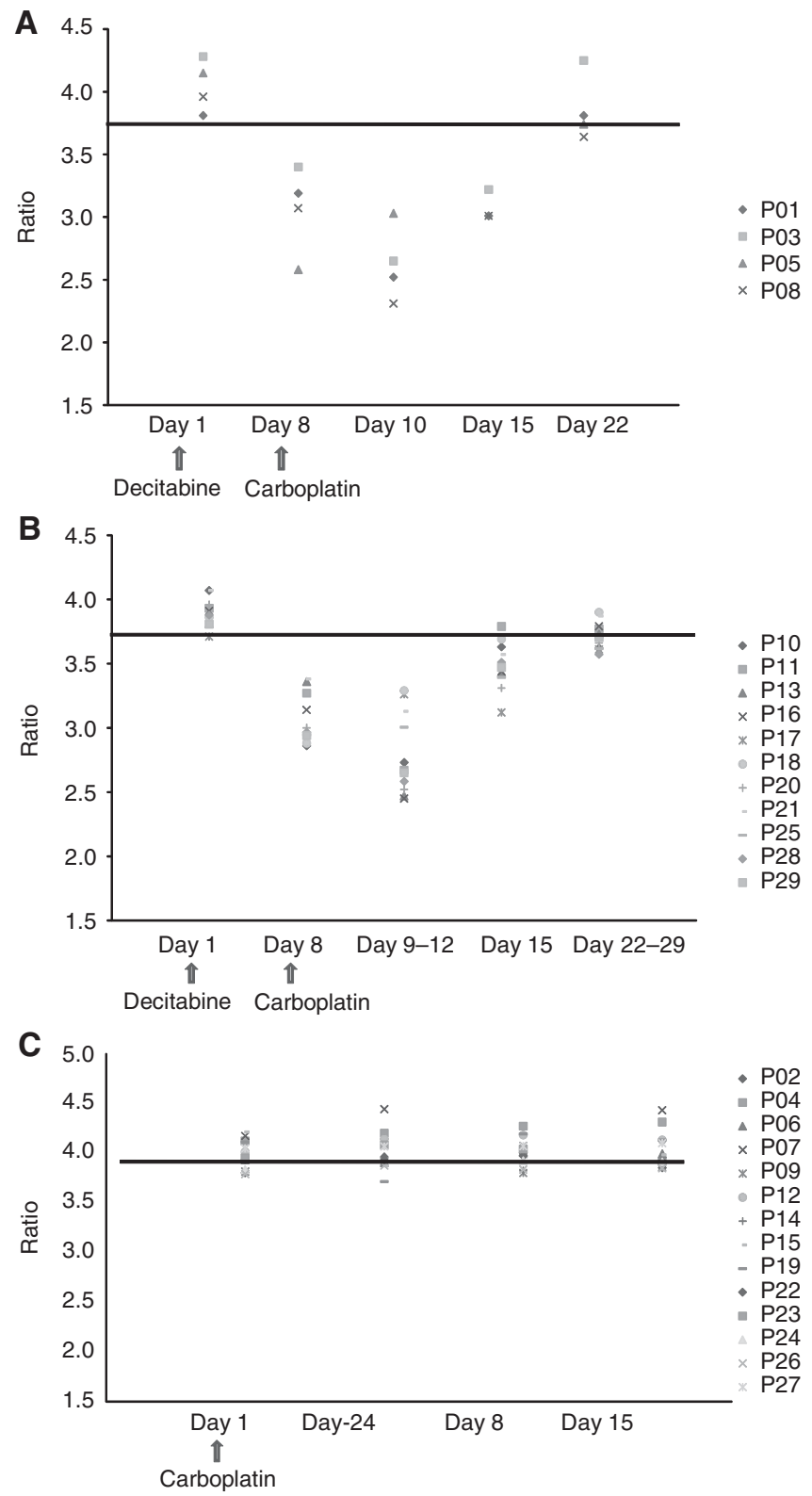

Figure 2. Changes in global methylation levels. Cycle 1 ratios of 5-methyl-2'-deoxycytidine to total cytidine in peripheral blood cells of patients receiving (A) $90 \mathrm{mg} \mathrm{m}^{-2}$ decitabine; (B) $45 \mathrm{mg} \mathrm{m}^{-2}$; and (C) carboplatin alone. The line represents the mean ratio in healthy volunteers.

In our phase I study, the maximal mean decrease in levels of 5-methyl-2'-deoxycytidine in peripheral mononuclear cell DNA was $33 \%$ in patients receiving $45 \mathrm{mg} \mathrm{m}^{-2}$ decitabine $v$ s $35 \%$ in patients receiving $90 \mathrm{mg} \mathrm{m}^{-2}$, indicating that $45 \mathrm{mg} \mathrm{m}^{-2}$ induced only marginally less demethylation (Appleton et al, 2007). In this study, both 90 and $45 \mathrm{mg} \mathrm{m}^{-2}$ of decitabine induced a decrease in global methylation comparable to the phase I. In xenograft models, doses of decitabine that cause sensitisation to carboplatin of xenografts in mice induce a $27 \%$ mean reduction in 5-methyl-2'-deoxycytidine levels in PBMC (Plumb et al, 2000). Thus, the reduction in 5-methyl-2'-deoxycytidine levels in PBMC seen in patients in this study was equivalent or greater to that observed in murine PBMC, with doses of decitabine that, in mice, produce concomitant demethylation, re-expression of epigenetically silenced genes and chemosensitisation in drug-resistant xenografts.

In the population included in this study, we found that the combination was not feasible at a dose of $90 \mathrm{mg} \mathrm{m}^{-2}$ of decitabine 
due to neutropenia. Hypersensitivity reactions also reduced the deliverability of the combination. This differed from the findings of the phase I study, but in this, dose-limiting toxicity was only assessed in the first cycle and few patients received more than two cycles, so the cumulative toxicity was not apparent. In the phase I study, the majority of patients had not had previous exposure to carboplatin and no hypersensitivity reactions occurred in these patients, so again this toxicity was not apparent until the phase II study.

Two other phase I studies have investigated the combination of a demethylating agent and carboplatin in ovarian cancer patients. Both included patients with disease relapsing within 6 months of their last carboplatin and both used 5-day schedules for the demethylating agent and carboplatin of AUC 4 or 5 on a 28-day schedule (Fang et al, 2010; Fu et al, 2011). Despite the relatively low dose intensity of carboplatin and more platinum-resistant populations, both studies saw responses (11\% and $13.8 \%)$, although in the study by Fu et al (2011), the majority of patients with platinum-resistant disease had received other therapy before study entry, and actual platinum-free intervals ranged from 6 to 31 months. Activity of the combination has been confirmed in a subsequent non-randomised phase II trial performed by Matei et al (2012), with a RR 35\% and median PFS of 10.2 months, which is certainly higher than would be expected in a platinum-resistant population treated with carboplatin alone. Interestingly, despite the lower dose of carboplatin (AUC 5 q 28days), Matei et al (2012) had to give peg-filgastrim to avoid prolonged neutropenia, and they also saw a high rate of hypersensitivity reactions (35\%).

The reason for our differing results is not clear. The low RR in our study was not explained by significant differences in carboplatin dose intensity (between Arm A and B45). In these other studies, the responses often occurred after several cycles, suggesting that more prolonged treatment with a demethylating agent than we achieved may be required. It is also possible that the 5-day schedule induced more prolonged demethylation during each cycle, which was more effective in reversing resistance. Alternatively, the inclusion of patients with $<6$ months PFS in these positive studies may have selected a group of patients more responsive to demethylating agents than the 6-12 month group. Indeed, it is possible that in our population decitabine caused demethylation of other genes, which resulted in a reduction rather than an increase in platinum sensitivity in some cases. An example might be BRCA1 where methylation is associated with response to platinum-based chemotherapy at presentation (Teodoridis et al, 2005). Hence, demethylation could have resulted in re-expression of BRCA1 and a decrease in sensitivity to carboplatin in the 6-12 month group, where it is conceivable that demethylation of BRCA may be less significant in the $<6$ month group when other mechanisms of platinum resistance may predominate.

Our study was designed to allow inclusion of sufficient patients with methylation of MLH1 CGI to allow separate analysis of this group; however, a lower than anticipated rate of MLH1 CGI methylation and early closure of the study meant that too few patients were included for this to be feasible. Interestingly, Matei et al (2012) found that demethylation of MLH1, RASSF1a and HOXA10/11 correlated positively with PFS $(P<0.05)$ supporting our original hypothesis.

The high incidence of hypersensitivity reactions contributed to the difficulty in delivering the combination therapy. The reason for this increase is unknown but is potentially the result of demethylation and re-expression of immune-modifying genes. Interleukin (IL)- 4 and interferon (IFN)- $\gamma$ are major cytokines that affect the differentiation of naive CD4 $+\mathrm{T}$ lymphocytes into the Th1 and Th2 lineage, which control IgE production, the mediator of hypersensitive reactions. The promoter regions are largely methylated in both the IL-4 and IFN- $\gamma$ genes in T-lymphocytes, and it has been suggested that demethylation correlates with increased expression and hence hypersensitivity (Kwon et al, 2008).
In conclusion, decitabine is difficult to deliver in combination with carboplatin AUC 6 on a 28-day schedule; moreover, in this patient group and using this schedule it definitely does not increase and may decrease the RR to carboplatin. Other demethylating agents are in development; these may be easier to deliver with less myelosuppression, and other schedules, for example, a 5-day schedule, may induce more marked and persistent demethylation. In addition, a greater understanding of the significance of methylation of specific genes is critically required in order to identify a population with drug-resistant ovarian cancer who may benefit most from this approach.

\section{ACKNOWLEDGEMENTS}

We thank the staff of the Beatson West of Scotland Cancer Centre; Royal Marsden Hospital; Mount Vernon Hospital; St Bartholomew's Hospital; Belfast City Hospital and Queen's University Belfast; Sheffield Weston Park Hospital; Edinburgh Western General Hospital; Glasgow Clinical Trials Unit; Beatson Analytical Services Unit; Scottish Gynaecological Cancer Trials Group; and the Drug Development Office of Cancer Research UK. Above all, we thank our patients, their families and friends for their support and participation in this trial. The protocol was developed at the ECCO/AACR/ASCO Workshop on 'Methods in Clinical Cancer Research' 2005. This work was supported by Cancer Research UK. CRUKD/07/065. Decitabine was provided by Eisai. We acknowledge the support of the Glasgow Experimental Cancer Medicine Centre and Cancer Research UK and UK Departments of Health Experimental Cancer Medicine Centre funding to our centres. MG and SBK acknowledge NHS funding to the NIHR Biomedical Research Centre.

\section{CONFLICT OF INTEREST}

The authors declare no conflict of interest.

\section{REFERENCES}

Appleton K, Mackay HJ, Judson I, Plumb JA, McCormick C, Strathdee G, Lee C, Barrett S, Reade S, Jadayel D, Tang A, Bellenger K, Mackay L, Setanoians A, Schätzlein A, Twelves C, Kaye SB, Brown R (2007) Phase I and pharmacodynamic trial of the DNA methyltransferase inhibitor decitabine and carboplatin in solid tumors. J Clin Oncol 25: 4603-4609.

Brown R, Hirst GL, Gallagher WM, McIlwrath AJ, Margison GP, van der Zee AG, Anthoney DA (1997) hMLH1 expression and cellular responses of ovarian tumour cells to treatment with cytotoxic anticancer agents. Oncogene 15: 45-52.

Chang X, Monitto CL, Demokan S, Kim MS, Chang SS, Zhong X, Califano JA, Sidransky D (2010) Identification of hypermethylated genes associated with cisplatin resistance in human cancers. Cancer Res 70: 2870-2879.

Dai W, Teodoridis JM, Graham J, Zeller C, Huang TH, Yan P, Vass JK, Brown R, Paul J (2008) Methylation Linear Discriminant Analysis (MLDA) for identifying differentially methylated CpG islands. BMC Bioinformatics 9: 337.

Fang F, Balch C, Schilder J, Breen T, Zhang S, Shen C, Li L, Kulesavage C, Snyder AJ, Nephew KP, Matei DE (2010) A phase 1 and

pharmacodynamic study of decitabine in combination with carboplatin in patients with recurrent, platinum-resistant, epithelial ovarian cancer. Cancer 116: 4043-4053.

Ferlay J, Shin HR, Bray F, Forman D, Mathers C, Parkin DM (2010) Estimates of worldwide burden of cancer in 2008: GLOBOCAN 2008. Int J Cancer 127: 2893-2917.

Fu S, Hu W, Iyer R, Kavanagh JJ, Coleman RL, Levenback CF, Sood AK, Wolf JK, Gershenson DM, Markman M, Hennessy BT, Kurzrock R, Bast RC (2011) Phase $1 \mathrm{~b}-2 \mathrm{a}$ study to reverse platinum resistance through use of a hypomethylating agent, azacitidine, in patients with platinum-resistant or platinum-refractory epithelial ovarian cancer. Cancer 117: 1661-1669. 
Gifford G, Paul J, Vasey PA, Kaye SB, Brown R (2004) The acquisition of hMLH1 methylation in plasma DNA after chemotherapy predicts poor survival for ovarian cancer patients. Clin Cancer Res 10: 4420-4426.

Glasspool RM, Teodoridis JM, Brown R (2006) Epigenetics as a mechanism driving polygenic clinical drug resistance. Br J Cancer 94: 1087-1092.

Graham JS, Kaye SB, Brown R (2009) The promises and pitfalls of epigenetic therapies in solid tumours. Eur J Cancer 45: 1129-1136.

Kantariian H, Oki Y, Garcia-Manero G, Huang X, O'Brien S, Cortes J, Faderl S, Bueso-Ramos C, Ravandi F, Estrov Z, Ferrajoli A, Wierda W, Shan J, Davis J, Giles F, Saba HI, Issa JP (2007) Results of a randomized study of 3 schedules of low-dose decitabine in higher-risk myelodysplastic syndrome and chronic myelomonocytic leukemia. Blood 109: 52-57.

Kwon NH, Kim JS, Lee JY, Oh MJ, Choi DC (2008) DNA methylation and the expression of IL-4 and IFN-gamma promoter genes in patients with bronchial asthma. J Clin Immunol 28: 139-146.

Matei D, Fang F, Shen C, Schilder J, Arnold A, Zeng Y, Berry WA, Huang T, Nephew KP (2012) Epigenetic resensitization to platinum in ovarian cancer. Cancer Res 72: 2197-2205.

Parmar MK, Ledermann JA, Colombo N, du Bois A, Delaloye JF, Kristensen GB, Wheeler S, Swart AM, Qian W, Torri V, Floriani I, Jayson G, Lamont A, Tropé C. Collaborators I, AGO (2003) Paclitaxel plus platinum-based chemotherapy vs conventional platinum-based chemotherapy in women with relapsed ovarian cancer: the ICON4/AGO-OVAR-2.2 trial. Lancet 361: 2099-2106.

Pfisterer J, Plante M, Vergote I, du Bois A, Hirte H, Lacave AJ, Wagner U, Stähle A, Stuart G, Kimmig R, Olbricht S, Le T, Emerich J, Kuhn W, Bentley J, Jackisch C, Lück HJ, Rochon J, Zimmermann AH, Eisenhauer E. AGO-OVAR, CTG N, GCG E (2006) Gemcitabine plus carboplatin compared with carboplatin in patients with platinum-sensitive recurrent ovarian cancer: an intergroup trial of the AGO-OVAR, the NCIC CTG, and the EORTC GCG. J Clin Oncol 24: 4699-4707.

Plumb JA, Strathdee G, Sludden J, Kaye SB, Brown R (2000) Reversal of drug resistance in human tumor xenografts by 2'-deoxy-5-azacytidine-induced demethylation of the hMLH1 gene promoter. Cancer Res 60: 6039-6044.
Rustin GJ, Vergote I, Eisenhauer E, Pujade-Lauraine E, Quinn M, Thigpen T, du Bois A, Kristensen G, Jakobsen A, Sagae S, Greven K, Parmar M, Friedlander M, Cervantes A, Vermorken J (2011) Definitions for response and progression in ovarian cancer clinical trials incorporating RECIST 1.1 and CA 125 agreed by the Gynecological Cancer Intergroup (GCIG). Int $J$ Gynecol Cancer 21: 419-423.

Scott NW, McPherson GC, Ramsay CR, Campbell MK (2002) The method of minimization for allocation to clinical trials. a review. Control Clin Trials 23: $662-674$.

Strathdee G, MacKean MJ, Illand M, Brown R (1999) A role for methylation of the hMLH1 promoter in loss of hMLH1 expression and drug resistance in ovarian cancer. Oncogene 18: 2335-2341.

Teodoridis JM, Hall J, Marsh S, Kannall HD, Smyth C, Curto J, Siddiqui N, Gabra H, McLeod HL, Strathdee G, Brown R (2005) CpG island methylation of DNA damage response genes in advanced ovarian cancer. Cancer Res 65: 8961-8967.

Wei SH, Balch C, Paik HH, Kim YS, Baldwin RL, Liyanarachchi S, Li L, Wang Z, Wan JC, Davuluri RV, Karlan BY, Gifford G, Brown R, Kim S, Huang TH, Nephew KP (2006) Prognostic DNA methylation biomarkers in ovarian cancer. Clin Cancer Res 12: 2788-2794.

Zeller C, Brown R (2010) Therapeutic modulation of epigenetic drivers of drug resistance in ovarian cancer. Ther Adv Med Oncol 2: 319-329.

Zeller C, Dai W, Steele NL, Siddiq A, Walley AJ, Wilhelm-Benartzi CS, Rizzo S, van der Zee A, Plumb JA, Brown R (2012) Candidate DNA methylation drivers of acquired cisplatin resistance in ovarian cancer identified by methylome and expression profiling. Oncogene 31: 4567-4576.

This work is published under the standard license to publish agreement. After 12 months the work will become freely available and the license terms will switch to a Creative Commons AttributionNonCommercial-Share Alike 3.0 Unported License. 